\title{
LXXVII. On electricity: in answer to Mr. Singer's remarks
}

\section{Ez. Walker Esq.}

To cite this article: Ez. Walker Esq. (1814) LXXVII. On electricity: in answer to Mr. Singer's remarks, Philosophical Magazine Series 1, 43:193, 364-366, DOI: 10.1080/14786441408638045

To link to this article: http://dx.doi.org/10.1080/14786441408638045

曲 Published online: 27 Jul 2009.

Submit your article to this journal ๘

Џ Article views: 2

Q View related articles ¿ 
trometer being withdrawn, the leaves still retained their diversence.

Exp. 3.-The electrometer was placed in contact with the glass tube near to the negative extremity of the column. The results were precisely the same as in the two preceding experiments, except that in this the divergence of the leaves was less than in those.

Exp. 4.-The electrometer was now put in contact with the waxed end of the glass tube next to the brass mounting at the positive extremity of the column. In a few seconds the leaves just separated with positive electricity, but the electrometer being withdrawn, they closed. As the leaves were thus found to be only influentially affected, the electrometer was replaced in its position; and after the space of a few minutes the leaves diverged something more than $\frac{1}{8}$ of an inch: the electrometer being withdrawn, the leaves remained positively electrified.

Exp. 5.-The electricity of the waxed end of the tube next to the brass mounting at the negative extremity of the column was next ascertained. The leaves at first were only influentially affected; but after the contact had been continued for several minutes, they remained positively electrified.

Exp. 6. - The negative extremity of the column was now insulated as well as the positive. The same places of the column were examined as before, and the results were similar to the preceding; the only difference being that the divergence of the leaves was much less than in the former instances.

Exp. 7.-The column was now taken and exposed to the fire for about three minutes, in order to dissipate all the moisture from its surface; it was then placed as in Experiment 1. and the electrometer applied to the different points in the manner already described. The kind of electricity found at each point was as before positive ; and now in no instance was any electricity communicated to the leaves, which diverged only while the electrometer was in contact with the column; their divergence was very small. I am, gentlemen, Your obedient and obliged servant, To Messrs. Nicholson and Tilloch. Thomas Howldy.

LXXVII. On Electricity: in Answer to Mr. SıNGER's Remarks. By Ez. WALKER, Esq. Lynn, May 18, 1814.

Sirs, - $M_{R}$. Singer still maintains that $I$ have fallen into error, in my experiments on inducted electricity, and has advanced three statements to prove it*.

$$
\text { * Phil. Mag. vol. xliii. p. } 20 .
$$


The first consists of a reprint of a paragraph from one of his former papers*, which contains nothing but Mr. Singer's positive assertions. Mr. S. then ards, "these are facts, which the constant repetition of such experiments professionally enables me to state with confidence."

But philosophical statements must be demonstrated, either mathematically, physically, or experimentally, ere they can be received as facts. For, as the bare word of Newton wonld never be taken on a philosophical subject without a demonstration, consequently the assertions of $\mathrm{Mr}$. S. cannot be admitted on any other terms.

Secondly, Mr. Singer says, "the statement in the preceding paragraph may be verified in a few minutes by any one sufficiently acquainted with the practice of electricity to make the experiments with due accuracy; and I believe it not only adduces a fact in proof of Mr. Walker's error, but offers the requisite information to show him its cause."

But the word belief is very objectionable, although it is the foundation on which Mr. S. builds his statement. The geometricians have not suffered this word to stain their pages once in 2000 years : and the experimental philosophers have, long ago, blotted it out of all their demonstrations.

Had Mr. S. understood the true meaning of this word, he would not have used it in the sense he has done. He has advanced it as a sound argument against iny experiments; but will he admit it as an argument against himself ? Let us try the experiment. If any one should say he believed that Mr. S. is a very superficial reasoner, it is ten to one that Mr. S. would admit the word belief, in this case, as a demonstration of the weakness of mental faculties. And if he will not admit this word as an argument against himself, he ought not to have used it against my experiments.

And thirdly, Mr. S. observes, "independent of this circumstance, it is amusing to find an individual so confident of the infallibility of his own observations, as to consider them sufficient to subvert the experience of Canton, Franklin, Wilke, Epinus, Cavallo, Stanhope, and Robison.

Whether Mr. S. intended this last statement as a specimen of his wit, or of his reasoning, I know not. But as Mr. S, will not, I presume, be offended at my mentioning the name of a great astronomer on the same page with his own, let it, therefore, be supposed that Mr. Singer had lived in the days of Copernicus-Mr. Singer might then have said, that " it was -very amusing to find an individual so confident of the infallibility of his own observations, as to consider them sufficient" to prove

$$
\text { * Phil. Mag. vol. xlii. p. } 204 .
$$


that the earth moved round the sun,--when all the world believed that it was stationary.

I am, gentlemen,

Your obedient servant,

Ez. Walker.

\section{To Messrs. Nicholson and Tilloch.}

LXXVIII. Process for preserving the Canvass in Oil Paintings, and refuiring Defects thercin. By Mr. Charciss Wison, Worcester-Street, Borough *

1st. Srparate the canvass from the pannel, or straining frame, and lay it on a smooth table, with the painting dowiswards, and nail it securely.

2d. Take a piece of tin foil, larger than the canvass, place it on a very smooth table, and make the tin foil as smooth as possible with your hand. Then melt some Salisbury glue, in the same manner as for cabinet-makers' use.

3d. Warm the tinfoil before the fire, and lay it again on the table, then wash it over with the glue, and place it on the back of the canvass, secured as above, as quick as possible; smooth it perfectly with the hand, and let it remain in a warm room to dry.

4th. To repair the cracks of the canvass, in an old oil painting, lay it on a very smooth table, the subject downwards; then, with a brush or fine linen, cover the canvass with some melted white wax, and, with a warm flat smoothing iron, rub over the wax, and press it hard, which will draw the colours up to the canvass.

5 th. To varnish the painting, clean the picture well, take some white wax, and spirits of turpentine, with a small quantity of linseed oil and sugar of lead; melt them over the fire, dip a fine linen rag therein, with which wash your painting; then, with a fine linen rag, rub over the varnish till it begins to be polished; let it remain till next day, and then rub it over with a fine waxed cloth, and afterwards with a soft linen cloth, using them alternately, by which means the painting will receive a very fine polish.

By the above means, the cracks and small holes in old paintings may be closed and repaired, and a coat of tin foil may be afterwards glued on the back of the canvass, as above mentioned.

A foot square of the tin foil costs about sixpence; when wanted of a larger size it will cost considerably more in proportion. It may be procured in sheets of three or four feet if wanted.

* From Transactions of the Suciety for the Encouragement of Arts, \& c. for 1819. - The Society roted ten guineas to Mr. Wilson for this communication.

LXXIX. Ex- 